\title{
Feasibility Assessment of Thermal Management System for Green Power Sources Using Nanofluid
}

\author{
Yi-Hsuan Hung, Jyun-Hong Chen, and Tun-Ping Teng \\ Department of Industrial Education, National Taiwan Normal University, No. 162, Sec. 1, He-ping East Road, \\ Section 1, Da-an District, Taipei City 10610, Taiwan \\ Correspondence should be addressed to Yi-Hsuan Hung; hungyh@ntnu.edu.tw
}

Received 20 July 2013; Accepted 2 August 2013

Academic Editor: Yanbao Zhao

Copyright (c) 2013 Yi-Hsuan Hung et al. This is an open access article distributed under the Creative Commons Attribution License, which permits unrestricted use, distribution, and reproduction in any medium, provided the original work is properly cited.

\begin{abstract}
A thermal management system using alumina $\left(\mathrm{Al}_{2} \mathrm{O}_{3}\right)$ /water as the nanofluid for green power sources was experimentally assessed in this paper. Basic thermal principles and formulas were utilized to evaluate the performance of an air-cooled heat exchanger. The $\mathrm{Al}_{2} \mathrm{O}_{3}$ /water nanofluid was produced at the concentrations of $0.5,1.0$, and $1.5 \mathrm{wt} . \%$. The testing conditions of this experiments were above three concentrations, five coolant flow rates $(0.8,1.2,1.6,2.0$, and $2.4 \mathrm{~L} / \mathrm{min}$.), and three heating powers $(50,100$, and $150 \mathrm{~W})$. Firstly, basic properties of nanoparticles were analyzed. Fundamental relationships of the $\mathrm{Al}_{2} \mathrm{O}_{3} /$ water nanofluid with respect to temperatures and concentrations were measured such as: viscosity, density, and specific heat. Next, an innovative concept named efficiency factor (EF) was proposed to quantitatively evaluate the thermal system performance. The enhancement of thermal system performance compared with distilled water was then defined as an efficiency factor ratio $\left(R_{\mathrm{EF}}\right)$. The experimental results demonstrated that the efficiency factor ratios were optimal at low flow rate $\left(0.8 \mathrm{~L} / \mathrm{min}\right.$.) and low concentration $(0.5 \%)$. Values of $R_{\mathrm{EF}}$ were all below 1.0 at high flow rates $(1.2-2.4 \mathrm{~L} / \mathrm{min}$.). This research points out the direction of optimizing a thermal management system for green energy sources in the near future.
\end{abstract}

\section{Introduction}

Green power sources have attracted much more attentions recently due to environmental concerns and corresponding stringent laws legislated. Proton exchange membrane fuel cells (PEMFCs), lithium batteries, and supercapacitors (or ultracapacitors) are widely applied in multiple industrial applications such as: uninterruptable power supplies (UPS), transportations, and even cellular phones [1]. There are three main approaches to raise overall efficiency as well as to enhance system performance: (1) system designs: to select components (subsystems) and arrange them appropriately for maximizing required outputs [2]; (2) control strategies: to track the required commands rapidly with associated actuators [3]; (3) thermal management: to maintain the highefficiency operation area of green energy sources [4].

For thermal management, previous studies mentioned that operation temperature is crucial for green power sources which significantly influences the system dynamics, increases the electric storage capacity, and even extends the life cycles
[5]. Hence, a thermal management system is required to be integrated with green power sources. For PEMFCs, the high-efficiency operation temperature is near $60^{\circ} \mathrm{C}$ [3]. Many research papers analyzed the thermal effect on fuel cells by thermal system modeling/simulation and experimental verification. For modeling and performance evaluation, lumpedparameter technique and quasiexperimental formulas were utilized in [6,7]. Steady and transient behaviors were investigated. Also in $[8,9]$, control-oriented thermal models were developed with a set of first-order nonlinear equations. Dynamics of key components were effectively modeled and designed. Various types of cooling systems and different subsystems for experimental FC thermal management system are also addressed in [10].

For energy storage devices (lithium batteries and supercapacitors), various thermal models were constructed. Plenty of experimental data was measured that the optimal operation temperatures for green energy storage systems are within $30^{\circ} \mathrm{C}$ to $50^{\circ} \mathrm{C}$. In $[11,12]$, a two-dimensional and a threedimensional battery thermal models were built to investigate 
the thermal dynamics. For a simpler thermal model with experimental-measuring variables proposed in [13], a set of first-order equations was developed for investigating temperature variation during battery charge and discharge period. In [14], the configurations of air-cooling/liquid-circulation systems were demonstrated. Besides lithium batteries, the thermal dynamics of SCs were also explored in [15].

In recent years, the problem of heat dissipation with features and strengthening functions of products has recently become more significant. Many approaches can improve the cooling system performance; the most feasible one is to enhance the heat transfer (dissipation) performance through the working fluid without modifying the mechanical designs or key components. Researchers have recently shown much interest on the issue of nanofluid thermal properties. Studies show that nanofluids enhance heat conduction performance due to their higher thermal conductivity than base fluids [1619]. The higher nanoparticle concentration and temperature will increase the random collision behavior which helps increase the thermal conductivity of nanofluid [20, 21]. However, some researchers believe that these factors do not cause a significant increase in thermal conductivity [22,23].

The heat convection characteristics must also be considered in practical heat exchange applications. Many researchers have focused on heat transfer properties of convection for a single pipe with different structures, and they investigated the parameters of nanoparticles added, pipe crosssection structure, materials and concentration of nanofluid, flow conditions, and other factors [24-28]. Research results showed that the nanofluid contains a better heat transfer fluid performance and will not increase the pressure drop caused by the increased viscosity of nanofluid too much.

Moreover, studies on the direct application of nanofluid for heat dissipation also present some valuable results. The nanofluid used in these studies consists mainly of $\mathrm{CuO} /$ water $[29,30], \mathrm{CuO} /$ ethylene glycol [31], $\mathrm{Al}_{2} \mathrm{O}_{3}$ /ethylene glycol [31, 32], $\mathrm{Al}_{2} \mathrm{O}_{3}$ /water [20,32-36], $\mathrm{Al}_{2} \mathrm{O}_{3}$ /ethylene glycol/water [37], $\mathrm{TiO}_{2}$ /water [35, 38], and $\mathrm{Ag} /$ methanol nanofluid [39]. Moreover, the heat exchanger used in these studies includes microchannel heat sink (MCHS) $[29,34,37]$, miniature plate heat exchanger [30], plate heat exchangers [31], doubletube flow heat exchanger $[31,38]$, radiator of diesel electric generator (DEG) [32], heat exchanger of a thermoelectric module [33], multichannel heat exchanger [20], shell and tube heat exchanger [35], finned tube heat exchanger [21,36], and thermosyphon heat exchanger [39]. The above results demonstrated that the nanofluid could improve heat transfer performance of heat exchangers. Nevertheless, some research results indicated that the nanofluid will increase the pressure drop of pipelines $[30,38,40,41]$, viscosity, and friction factor $[34,41]$. It will also increase the pumping energy consumption $[34,36,41]$. Although the nanofluid could improve the cooling performance of heat exchanger, the excessive pumping energy consumption might result in the decrease of overall system efficiency. It is particularly for the use in electric vehicles and other green power systems. The power consumption of coolant pump might be comparatively large which leads to the heavier electric load of green power sources. The driving distance of vehicles will thus be shortened. Therefore, the overall cooling system performance requires in-depth consideration in order to confirm the practicality of nanofluids applied in green energy sources.

This study employs a direct synthesis method to produce $\mathrm{Al}_{2} \mathrm{O}_{3}$ /water nanofluid, which is served as coolant in a thermal management system. Firstly, the concentrations and temperatures of nanofluid which affect the density, specific heat, and viscosity of nanofluid are examined. The experimental results will be compared with the calculated results by related equations to evaluate the feasibility of the theoreticalbased density, specific heat, and viscosity applied in a real system. Then, the heat dissipation capability of green energy sources will be emulated under different waste-heat powers. In this study, how nanofluid weight fractions, flow rates, and generated power affect the performance of an aircooled heat exchanger and pumping power is focused. A self-defined index: efficiency factor (EF) and the concept of enhanced ratio are utilized to evaluate the feasibility of applying $\mathrm{Al}_{2} \mathrm{O}_{3}$ /water nanofluid in the thermal management system of green power sources.

\section{Related Theories for Heat Exchange}

To evaluate the heat dissipation of working fluids for the heat exchanger according to the measured inlet-outlet temperature difference $\left(T_{i}-T_{o}\right)$ regarding various mass flow rates $\left(\dot{m}_{l}\right)$ and specific heat $\left(c_{p, l}\right)$, the heat dissipation capacity $\left(\dot{Q}_{d}\right)$ of the heat exchanger can be written as

$$
\dot{Q}_{d}=\dot{m}_{l} c_{p, l}\left(T_{i}-T_{o}\right) \text {. }
$$

The mass flow rate $\left(\dot{m}_{l}\right)$ in (1) can be further expressed as the volume flow rate $\left(\dot{G}_{l}\right)$ multiplied by the density of the liquid $\left(\rho_{l}\right)$

$$
\dot{m}_{l}=\dot{G} \times \rho_{l} .
$$

Based on the concept of the solid-liquid mixture, the density $\left(\rho_{\mathrm{nf}}\right)$ and specific heat $\left(c_{p, \mathrm{nf}}\right)$ of the $\mathrm{Al}_{2} \mathrm{O}_{3}$ /water nanofluid were derived using (3) and (4), which are linearly related to volume fraction $(\phi)$, bulk fluid density $\left(\rho_{\mathrm{bf}}\right)$, nanoparticle density $\left(\rho_{p}\right)$, bulk fluid specific heat $\left(c_{p, b f}\right)$, and nanoparticle specific heat $\left(c_{p, p}\right)[16,21,42,43]$ :

$$
\begin{gathered}
\rho_{\mathrm{nf}}=(1-\phi) \rho_{\mathrm{bf}}+\phi \rho_{p}, \\
c_{p, \mathrm{nf}}=(1-\phi) c_{p, \mathrm{bf}}+\phi c_{p, p} .
\end{gathered}
$$

Brinkman [44] proposed an equation of the relationship among the viscosity of nanofluid $\left(\mu_{\mathrm{nf}}\right)$, viscosity of bulk fluid $\left(\mu_{\mathrm{bf}}\right)$, and the volume fraction $(\phi)$ of added nanoparticles. The equation estimates the influence of the concentration of added nanoparticles on the viscosity of fluid. It is expressed as

$$
\frac{\mu_{\mathrm{nf}}}{\mu_{\mathrm{bf}}}=\frac{1}{(1-\phi)^{2.5}} .
$$

The volume fraction of the $\mathrm{Al}_{2} \mathrm{O}_{3}$ /water nanofluid was derived using (6). It can be calculated using nanofluid density 
$\left(\rho_{\text {nf }}\right)$, nanoparticle density $\left(\rho_{p}\right)$, nanoparticle weight $\left(W_{p}\right)$, and nanofluid weight $\left(W_{\mathrm{nf}}\right)$ as follows:

$$
\phi=\frac{\left(W_{p} / \rho_{p}\right)}{\left(W_{\mathrm{nf}} / \rho_{\mathrm{nf}}\right)}=\omega\left(\frac{\rho_{\mathrm{nf}}}{\rho_{p}}\right) .
$$

Equation (6) can be used to convert the weight fraction to volume fraction to calculate the density, specific heat and viscosity of the nanofluid using (3)-(5). The density and specific heat of the nanofluid and experimental data can be used to calculate the heat dissipation of the nanofluid.

Considering the heat dissipation capability of the thermal management system, the relationship of heat dissipation capacity $\left(\dot{Q}_{d}\right)$ and power consumption of the cooling components $\left(\dot{Q}_{p c}\right)$ must be simultaneously considered. Therefore, the performance of the heat dissipation for the cooling system can use the self-defined index (efficiency factor (EF)), formulated as

$$
\mathrm{EF}=\frac{\dot{Q_{d}}}{\dot{Q_{p c}}}=\frac{\dot{Q_{d}}}{\left(\dot{Q}_{p u}+\dot{Q}_{f}\right)} .
$$

In (7), the physical meaning of EF is the specific heat dissipation of the thermal management system. It is defined as the amount of waste heat generated by green power sources that can be removed per power consumed by the cooling components. In this study, the power of the coolant pump $\left(\dot{Q}_{p u}\right)$ and power of the fan $\left(\dot{Q}_{f}\right)$ were considered. EF can simultaneously evaluate the power consumption of the cooling components and the enhanced capacity of heat dissipation.

\section{Experimental Design and Process}

3.1. Preparation of $\mathrm{Al}_{2} \mathrm{O}_{3} /$ Water Nanofluid. Figure 1 shows the transmission electron microscope (TEM, JEOLJEM2000FXII, Japan) photographs of $\mathrm{Al}_{2} \mathrm{O}_{3}$ nanoparticles (Al-13P, Yong-Zhen Technomaterial, Taiwan). The figure shows that the $\mathrm{Al}_{2} \mathrm{O}_{3}$ nanoparticles aggregated, and the primary particle size is approximately $20 \mathrm{~nm}$. The crystallization and density of $\mathrm{Al}_{2} \mathrm{O}_{3}$ nanoparticles were $\gamma$-alumina and approximately $3880 \mathrm{~kg} / \mathrm{m}^{3}$, respectively, which refer to the data sheet of the dealer and studies $[21,36]$.

The $\mathrm{Al}_{2} \mathrm{O}_{3}$ /water nanofluid produced using a two-step synthesis method was employed as the experimental sample. First, the base liquid was prepared by adding $0.2 \mathrm{wt} . \%$ of cationic dispersant (water-soluble chitosan) to distilled water as a dispersant to maintain optimal dispersion performance for the nanofluid. To use chitosan as a cationic polymer without dissolving in water, it must be processed using organic acids to form water-soluble chitosan. It has nontoxic and biodegradable features and is widely used in medicine, agriculture, chemical, and food processing areas without causing environmental pollution [45]. Therefore, this study used it as a dispersant for $\mathrm{Al}_{2} \mathrm{O}_{3}$ /water nanofluids $[20,21,36]$.

The method of adding $\mathrm{Al}_{2} \mathrm{O}_{3}$ nanoparticles is to add the required weight of the nanoparticles to the base liquid divided several times. This method can effectively reduce the agglomeration phenomenon. When adding nanoparticles to the liquid, we used an electromagnetic stirrer and ultrasonic vibration for dispersion until the particles were uniformly dispersed before the subsequent addition. Finally, when adding the nanoparticles to the desired weight, electromagnetic agitation, a homogenizer, and ultrasonic vibration were alternately used for approximately $3 \mathrm{~h}$ for dispersing the $\mathrm{Al}_{2} \mathrm{O}_{3}$ nanoparticles into three weight fractions $(0.5,1.0$, and 1.5 wt.\%) to maintain the nanoparticles with a stable suspension in the base liquid. We used lower concentrations of nanofluid to prevent the heat pipes from being blocked by the sedimentation of nanoparticles. In other words, fluid viscosity increases and may choke the pipes or heat exchanger channels with the high concentration of nanofluid. Though low-concentration nanofluid might avoid this problem, based on our previous research, the concentration below $0.5 \mathrm{wt} . \%$ of the $\mathrm{Al}_{2} \mathrm{O}_{3}$ nanofluid cannot obviously rise the heat transfer coefficient. Moreover, a very low concentration of nanofluid might cause the inaccuracy of adding nanoparticles due to the precision of electronic balance and the process of nanofluid production. According to these reasons, we chose concentrations of $0.5,1.0$, and $1.5 \mathrm{wt} . \%$. All completed experimental samples were statically placed for seven days to examine the suspension performance. The concentration was subsequently examined using a UV/VIS spectrometer (BRC112E, B\&W, USA), and the changes were less than 5\%.

3.2. Experimental Setup and Design. To consider the use of $\mathrm{Al}_{2} \mathrm{O}_{3}$ /water nanofluids for heat dissipation for green power sources (PEMFCs, Li-ion batteries, and supercapacitors) in the near future, the temperature range of the samples for density, specific heat, and viscosity tests was set from 30 to $60^{\circ} \mathrm{C}$ to meet the regular operation conditions of these sources. The experimental results and the calculation results from (3)-(5) were compared to assess these equations.

For the density and viscosity experiments, a thermostatic bath (D-620, DengYng, Taiwan) was used to stabilize the temperature of the sample until it reached the expected temperature (approximately $30-60 \pm 0.5^{\circ} \mathrm{C}$ ). A quantitative pipette (DV-1000, HTL, Poland) at an accuracy of $\pm 0.6 \%$ with a precision electronic balance (XS125A, Precisa, Switzerland) at a precision of $\pm 0.1 \mathrm{mg}$ was used to measure the nanofluid density at 1 c.c. The accuracy of the density was calculated as $\pm 1.17 \%$. A portable viscometer (Viscolite VL700T15, Hydramotion, UK) with a measurement error of less than $\pm 1.0 \%$ was used to measure the viscosity. For the specific heat experiments, a differential scanning calorimeter (DSC, Q20, TA, USA) with a measurement error of $\pm 1.0 \%$ was used at various weight fractions and sample temperatures. The particle size and zeta potential of $\mathrm{Al}_{2} \mathrm{O}_{3}$ /water nanofluid were subsequently measured using a dynamic light-scattering (DLS) size/zeta potential analyzer (SZ-100, HORIBA, Japan) to determine the clustering and suspension performance at $25^{\circ} \mathrm{C}$.

In the heat dissipation experiment, a multichannel heat exchanger with a heater was used to simulate the various heat dissipations of green energy sources and evaluate the cooling performance of nanofluid using air-cooled heat exchangers. The operation conditions were concentrations of $0.5,1.0$, and 1.5 wt.\%; heating powers of 50,100, and $150 \mathrm{~W}$; nanofluid 


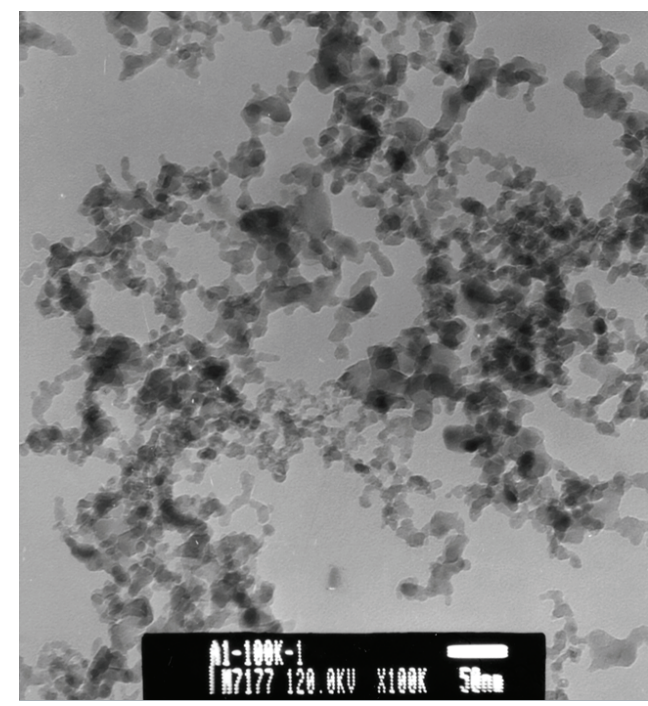

FIGURE 1: TEM images of $\mathrm{Al}_{2} \mathrm{O}_{3}$ nanoparticles.

flow rates of $0.8,1.2,1.6,2.0$, and $2.4 \mathrm{~L} / \mathrm{min}$. Figure 2 shows the experimental setup of the thermal management system. The nanofluid was pumped into the cooling system as the working liquid for heat dissipation after 800 c.c. of test samples was poured into a $0.8 \mathrm{~L}$ acrylic tank (reservoir) divided by several times in the running state, and the heating power was controlled using tubular heaters $(100 \mathrm{w} \times 2)$ and a programmable power supply (EV202, Consort, Belgium) at a resolution of $1.0 \mathrm{~W}$.

Through the measurement of temperature difference and flow rate between the inlet and outlet of liquid in the heat exchanger, the heat exchange capacity of the coolant was calculated using the inlet-output temperature difference and the basic properties (density and specific heat) of the experimental results. The air-cooled heat exchanger was made of aluminum, and its structure was a finned-tube type with a fan $[21,36]$. The pipe line was covered by thermal insulation material at a thickness of $1.5 \mathrm{~cm}$ to reduce the heat convection of ambient temperature. The mass flow rate of the liquid side was controlled by the input voltage (GPC-6030D, GWINSTEK, Taiwan) of the circulating pump (MCP-655, Swifttech, USA). The environmental control system maintained the temperature and relative humidity at $25 \pm 1^{\circ} \mathrm{C}$ and $60 \pm 5 \%$, respectively, and ensured consistent environmental conditions to reduce the deviation of the experiment. A data logger (TRM-20, TOHO, Japan), a pressure transducer (JPT-131LJ, Jetec, Taiwan) with an accuracy of $\pm 0.5 \%$, and a flow meter (NF05, Aichi Tokei, Japan) with an accuracy of $\pm 2.0 \%$ were used to measure the temperatures, pressures, and coolant flow rates, respectively, to coordinate with the relevant equations to calculate the heat dissipation and efficiency factor (EF) of the thermal management system.

3.3. Uncertainty and Data Analysis. In the pumping power experiment, the power was determined by reading the data logger for the voltage and loading resistor. The uncertainty in the pumping power experiment $\left(u_{m, p c}\right)$ can be expressed as

$$
u_{m, p}=\sqrt{\left(\frac{\Delta V_{t}}{V_{t}}\right)^{2}+\left(\frac{\Delta R_{s}}{R_{s}}\right)^{2}} .
$$

Equation (8) is a function of the voltage from the data logger $\left(V_{t}\right)$ and the loading resistor $\left(R_{s}\right)$ for evaluating the consumed power. The precision of the data logger of voltage was within $\pm 1 \%$. The precision of the loading resistor was within $\pm 5 \%$. Hence, the uncertainty of the pumping power experiment was less than $\pm 5.1 \%$.

In the heat dissipation experiment of nanofluid, the mass flow rates $(\dot{m})$ were measured using a flow meter $(\dot{G})$ and density of liquid $(\rho)$, and the temperature $(T)$ was determined using the thermocouples (T-type). The specific heat was measured using a DSC. The uncertainty of the experimental results is expressed as

$$
u_{m, d}=\sqrt{\left(\frac{\Delta \dot{G}}{\dot{G}}\right)^{2}+\left(\frac{\Delta \rho}{\rho}\right)^{2}+\left(\frac{\Delta T}{T}\right)^{2}} .
$$

The accuracy of the flow meter was $\pm 2.0 \%$. The accuracy of the measurement device for liquid density was $\pm 1.17 \%$. The accuracy of the DSC was $\pm 1 \%$. The resolution of the thermocouple was $\pm 0.5^{\circ} \mathrm{C}$. Therefore, the experimental uncertainty of the heat exchange capacity was less than $\pm 3.0 \%$.

To easily and quantitatively compare the enhancement of the thermal system performance using nanofluid with distilled water, we defined the concept of the efficiency factor ratio. According to EF expressed in (7), $R_{\mathrm{EF}}$ was formulated as the $\mathrm{EF}$ of the nanofluid $\left(\mathrm{EF}_{\mathrm{nf}}\right)$ divided by the $\mathrm{EF}$ of bulk fluid $\left(\mathrm{EF}_{\mathrm{bf}}\right)$ as follows:

$$
R_{\mathrm{EF}} \equiv \frac{\mathrm{EF}_{\mathrm{nf}}}{\mathrm{EF}_{\mathrm{bf}}}
$$

Equation (10) can be rewritten as

$$
R_{\mathrm{EF}} \equiv \frac{\mathrm{EF}_{\mathrm{nf}}}{\mathrm{EF}_{\mathrm{bf}}}=\frac{\left(\dot{Q}_{d, \mathrm{nf}} / \dot{Q}_{p, \mathrm{nf}}\right)}{\left(\dot{Q}_{d, \mathrm{bf}} / \dot{Q}_{p, \mathrm{bf}}\right)}=\frac{\left(\dot{Q}_{d, \mathrm{nf}} / \dot{Q}_{d, \mathrm{bf}}\right)}{\left(\dot{Q}_{p, \mathrm{nf}} / \dot{Q}_{p, \mathrm{bf}}\right)} .
$$

Equation (11) also contained the physical meaning, that is, the enhancement (nanofluid to distilled water) of heat dissipation capacity divided by the enhancement of pumping power consumption (nanofluid to distilled water).

\section{Results and Discussion}

Figure 3 shows the average size of the nanoparticle and zeta potential of the $\mathrm{Al}_{2} \mathrm{O}_{3}$ nanoparticles suspended in the base liquid. The $Z$-average particle size and zeta potential are $152.9 \mathrm{~nm} / 32.4 \mathrm{mV}, 162.5 \mathrm{~nm} / 44.4 \mathrm{mV}$, and $126.4 \mathrm{~nm} / 49.0 \mathrm{mV}$ at $0.5 \mathrm{wt} . \%, 1.0 \mathrm{wt} . \%$, and $1.5 \mathrm{wt} . \%$, respectively. The results indicated that the zeta potential of nanoparticles changed from negative to positive after the addition of the cationic 


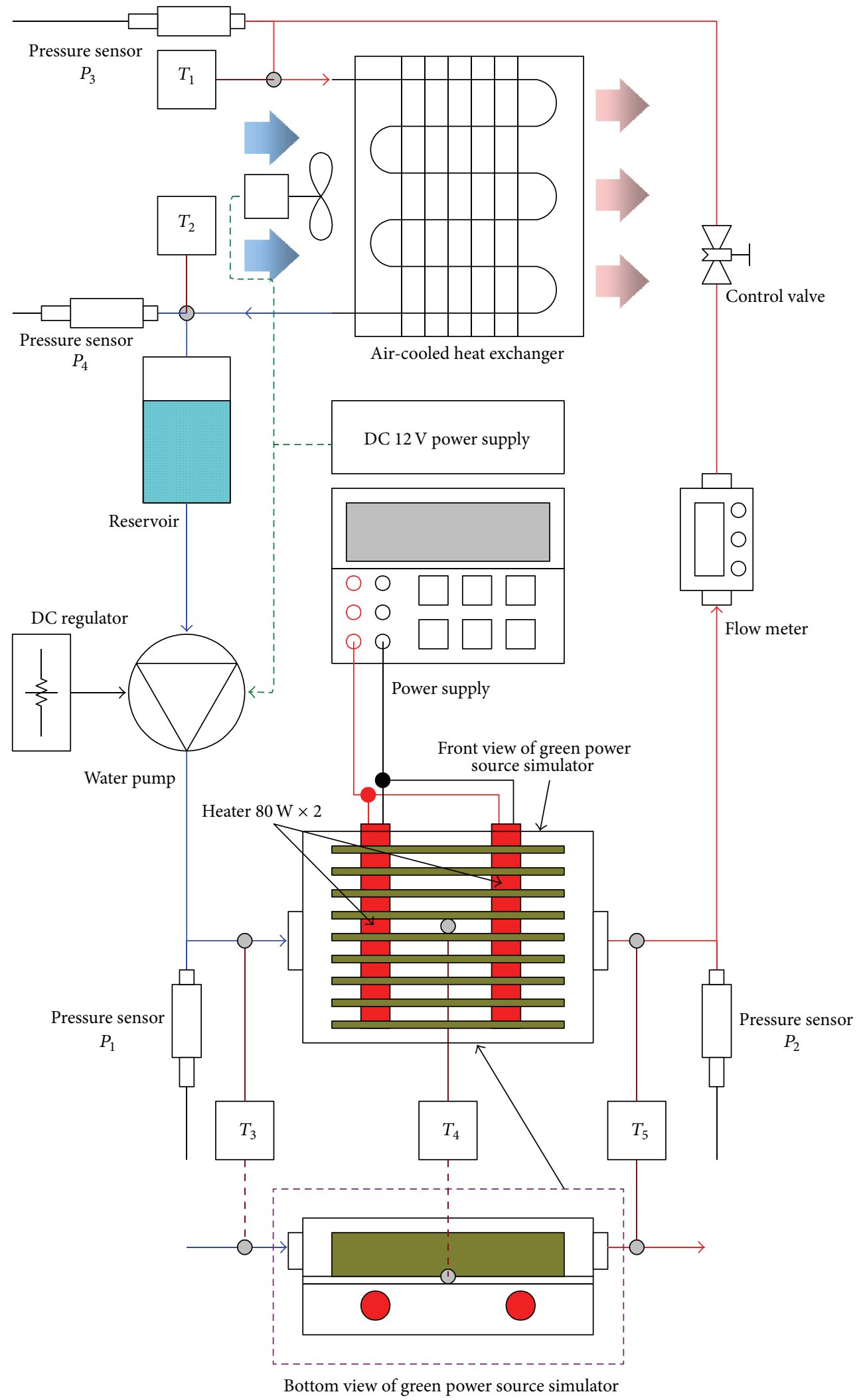

FIGURE 2: Experimental setup of heat dissipation for green power sources. 


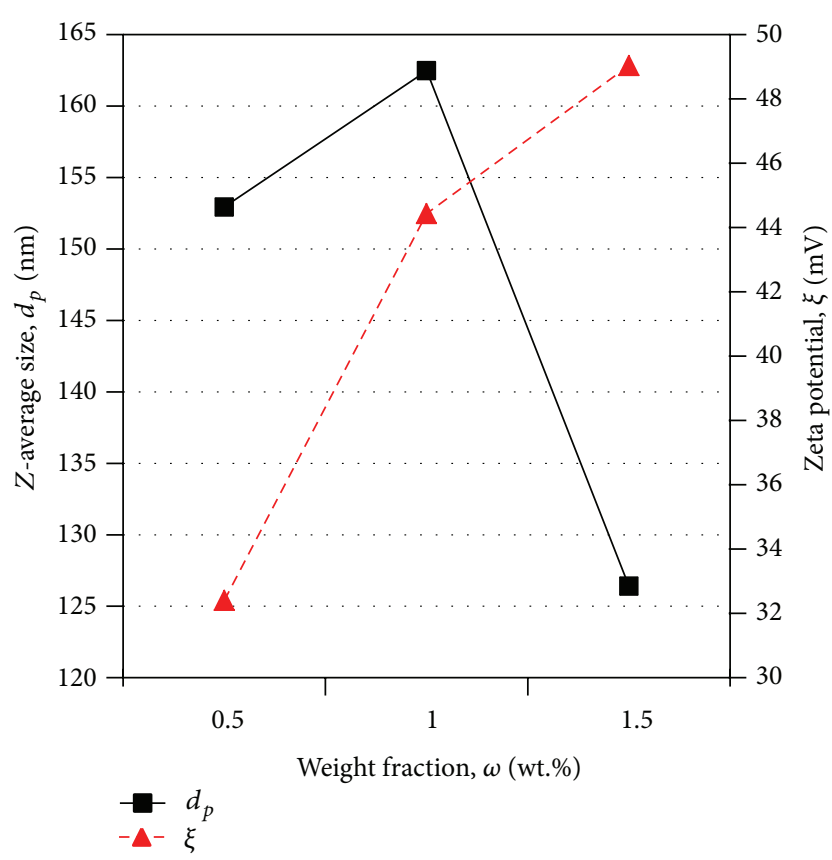

FIGURE 3: The average particle size and zeta potential for the $\mathrm{Al}_{2} \mathrm{O}_{3}$ nanoparticles suspended in base liquid.

dispersant (chitosan). The zeta potential away from the isoelectric point helps enhance the nanoparticle suspension performance. Furthermore, the zeta potential rises with the increase of $\mathrm{Al}_{2} \mathrm{O}_{3}$ weight fraction. It is because the $\mathrm{Al}_{2} \mathrm{O}_{3}$ nanoparticles in this study are weak acids, which means that the weight fraction directly influences the $\mathrm{pH}$ value of the nanofluid. And, the $\mathrm{pH}$ value thereby influences the zeta potential. The tested particle size from the DLS size/zeta potential analyzer exceeded the particle size observed using TEM. This was caused by the difference of the test principle and agglomeration of nanoparticles in the base liquid; therefore, the tested particle size was greater than that observed using TEM (Figure 1).

The first column in Table 1 shows the changes in specific heat for nanofluid at various temperatures and concentrations over a temperature range of $30-60^{\circ} \mathrm{C}$. Table 1 shows that the increase in added concentration reduces the specific heat of nanofluids, whereas the increase in temperature raises the specific heat of nanofluids. Because the specific heat of $\mathrm{Al}_{2} \mathrm{O}_{3}$ nanoparticles (approximately $0.77-0.8 \mathrm{~kJ} / \mathrm{kg} \cdot \mathrm{K}$ ) is less than that of water (approximately $4.18 \mathrm{~kJ} / \mathrm{kg} \cdot \mathrm{K}$ ), the added $\mathrm{Al}_{2} \mathrm{O}_{3}$ nanoparticles in water reduce the specific heat of the nanofluid. For a concentration of $0.5 \mathrm{wt} . \%$ and a temperature in the range of $30-60^{\circ} \mathrm{C}$, the specific heat increased by $1.37 \%-1.49 \%$. For a concentration of $1.0 \mathrm{wt} . \%$, the specific heat increased by $-2.10 \%$ to $-2.30 \%$. For a concentration of 1.5 wt. $\%$, the specific heat increased by $-3.80 \%$ to $-4.37 \%$ compared to distilled water. The specific heat increased for 0.5 wt. $\%$ of the $\mathrm{Al}_{2} \mathrm{O}_{3}$ is because of the added dispersant (0.2 wt.\% water-soluble chitosan). Because the specific heat of the dispersant is higher than that of water, adding a low concentration of nanoparticles does not substantially reduce the specific heat. However, an increased concentration of nanoparticles resulted in a downward trend for the specific heat of $\mathrm{Al}_{2} \mathrm{O}_{3}$ /water nanofluid.

The column also shows that the calculated results of specific heat using (4) were overestimated compared to the experimental results. The range of deviation between the experimental results and the calculated results was from $-1.57 \%$ to $4.24 \%$ for the specific heat. However, considering the uncertainty of the experiment, this deviation is within an acceptable range $(\fallingdotseq 5 \%)$. Because of the soluble property and variable specific heat of chitosan, (4) was unsuitable for the calculation in this case.

The second column in Table 1 demonstrates the changes in density for nanofluid. It shows that the increase in concentration enhances the density of nanofluids, whereas the increase in temperature reduces the density of nanofluids. For a concentration of $0.5 \mathrm{wt} . \%$ and a temperature in the range of $30-60^{\circ} \mathrm{C}$, the density increased by $0.61 \%-0.73 \%$. For a concentration of $1.0 \mathrm{wt} . \%$, the density increased by $1.20 \%-$ $1.92 \%$. For a concentration of $1.5 \mathrm{wt} . \%$, the density increased by $1.31 \%-2.32 \%$ compared to distilled water.

It also shows that the calculated results of density using (3) were mostly underestimated compared with the density of the experimental results. The range of deviation between the experimental results and the calculated results was from $-0.06 \%$ to $0.08 \%$ for the density. The nanoparticle volume fraction in (3) was transformed from the nanoparticle weight fraction using the true density of nanoparticles to unify the concentration of units using (6). However, considering the uncertainty of the experiment, this deviation was within an acceptable range. Therefore, (3) was suitable for estimating the density of $\mathrm{Al}_{2} \mathrm{O}_{3}$ /water nanofluids.

The third column shows the changes in viscosity for $\mathrm{Al}_{2} \mathrm{O}_{3}$ /water nanofluid at various temperatures and concentrations. In general, the nanofluid viscosity increased by adding more nanoparticles in the base liquid. For a concentration of $0.5 \mathrm{wt} . \%$ and within a temperature range of $30-60^{\circ} \mathrm{C}$, the viscosity increased by $4.76 \%-14.29 \%$. For a concentration of $1.0 \mathrm{wt} . \%$, the viscosity increased by $11.54 \%-$ $18.18 \%$. For a concentration of $1.5 \mathrm{wt} . \%$, the viscosity increased by $15.38 \%-27.27 \%$. These results show that the viscosity of $\mathrm{Al}_{2} \mathrm{O}_{3}$ /water nanofluid is higher than that of water. Because the viscosity affects the power consumption of the pump and the transport properties, the pumping power consumption must be considered when the $\mathrm{Al}_{2} \mathrm{O}_{3}$ /water nanofluid is applied in the thermal management system.

The third column also shows the calculated results of viscosity by (5), which were underestimated compared to the experimental results. The range of deviation between the experimental results and the calculated results was from $-14.55 \%$ to $0.32 \%$. The deviation increased with the concentration. This indicates that (5) was suitable for estimation in low concentrations of nanofluid.

After measuring the physical properties of $\mathrm{Al}_{2} \mathrm{O}_{3}$ /water nanofluid, the assessment of the heat dissipation system for green power sources was conducted; the experimental setup is shown in Figure 2. Various operating conditions were used, including five coolant flow rates $(0.8,1.2,1.6,2.0$, and $2.4 \mathrm{~L} / \mathrm{min})$, three concentrations $(0.5,1.0$, and $1.5 \mathrm{wt} . \%)$, 
TABLE 1: Specific heat, density, and viscosity of nanofluid at various temperatures and concentrations.

\begin{tabular}{|c|c|c|c|c|c|c|c|c|}
\hline \multirow{2}{*}{ Item } & \multirow{2}{*}{$T$} & \multirow{2}{*}{ Water } & \multicolumn{3}{|c|}{ Experimental data } & \multicolumn{3}{|c|}{ Calculation data ${ }^{*}$} \\
\hline & & & 0.5 wt. $\%$ & 1.0 wt. $\%$ & 1.5 wt. $\%$ & 0.5 wt. $\%$ & 1.0 wt. $\%$ & 1.5 wt. $\%$ \\
\hline \multirow{4}{*}{ Specific heat (cp) } & 30 & 4.18 & 4.24 & 4.09 & 4.00 & 4.18 & 4.17 & 4.17 \\
\hline & 40 & 4.18 & 4.24 & 4.09 & 4.00 & 4.18 & 4.17 & 4.17 \\
\hline & 50 & 4.18 & 4.24 & 4.09 & 4.01 & 4.18 & 4.17 & 4.17 \\
\hline & 60 & 4.19 & 4.25 & 4.10 & 4.03 & 4.18 & 4.18 & 4.17 \\
\hline \multirow{4}{*}{ Density } & 30 & 995.60 & 1002.30 & 1014.70 & 1018.70 & 1001.73 & 1005.49 & 1009.29 \\
\hline & 40 & 991.67 & 997.70 & 1009.30 & 1012.30 & 995.93 & 999.70 & 1003.51 \\
\hline & 50 & 986.00 & 993.00 & 1002.00 & 1004.00 & 991.74 & 995.51 & 999.33 \\
\hline & 60 & 980.99 & 988.20 & 992.80 & 993.80 & 986.94 & 990.73 & 994.55 \\
\hline \multirow{4}{*}{ Viscosity } & 30 & 0.70 & 0.80 & 0.83 & 0.88 & 0.75 & 0.75 & 0.76 \\
\hline & 40 & 0.65 & 0.70 & 0.73 & 0.75 & 0.68 & 0.68 & 0.68 \\
\hline & 50 & 0.55 & 0.63 & 0.65 & 0.70 & 0.60 & 0.60 & 0.61 \\
\hline & 60 & 0.53 & 0.55 & 0.60 & 0.65 & 0.55 & 0.55 & 0.56 \\
\hline
\end{tabular}

* Note: the calculation data of specific heat is calculated by (3), the calculation data of density is calculated by (4), and the calculation data of viscosity is calculated by (5).

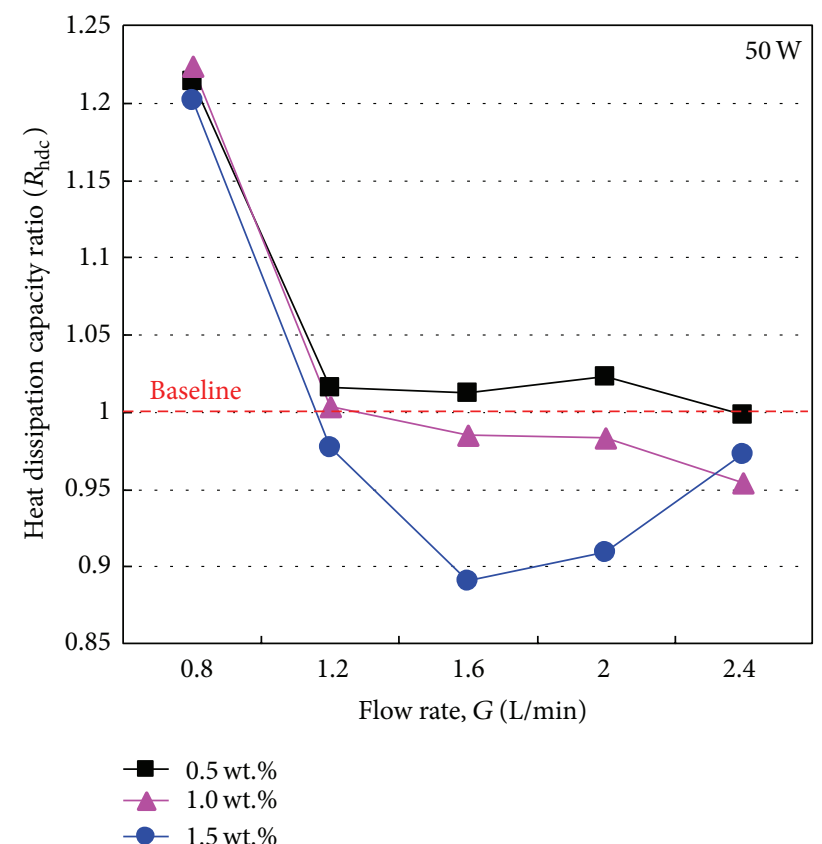

Figure 4: Heat dissipation capacity ratio of $\mathrm{Al}_{2} \mathrm{O}_{3}$ /water nanofluid at various flow rates and concentrations with heat generation of $50 \mathrm{~W}$.

and three cases of generated heat from pseudo-green power sources $(50,100$, and $150 \mathrm{~W})$.

Figures 4, 5, and 6 show the heat dissipation capacity ratios $\left(R_{\mathrm{hdc}} \equiv \dot{Q}_{d, \mathrm{nf}} / \dot{Q}_{d, \mathrm{bf}}\right)$ at various flow rates and concentrations for three heating powers. These figures show that the optimal heat exchange occurs at low flow rates. However, the increased concentration of $\mathrm{Al}_{2} \mathrm{O}_{3}$ reduced the heat dissipation capability. This is mainly attributed to the difference of densities between nanoparticles and water. Because the density of a nanoparticle is approximately 4 times that of water, the nanofluid can maintain excellent suspension

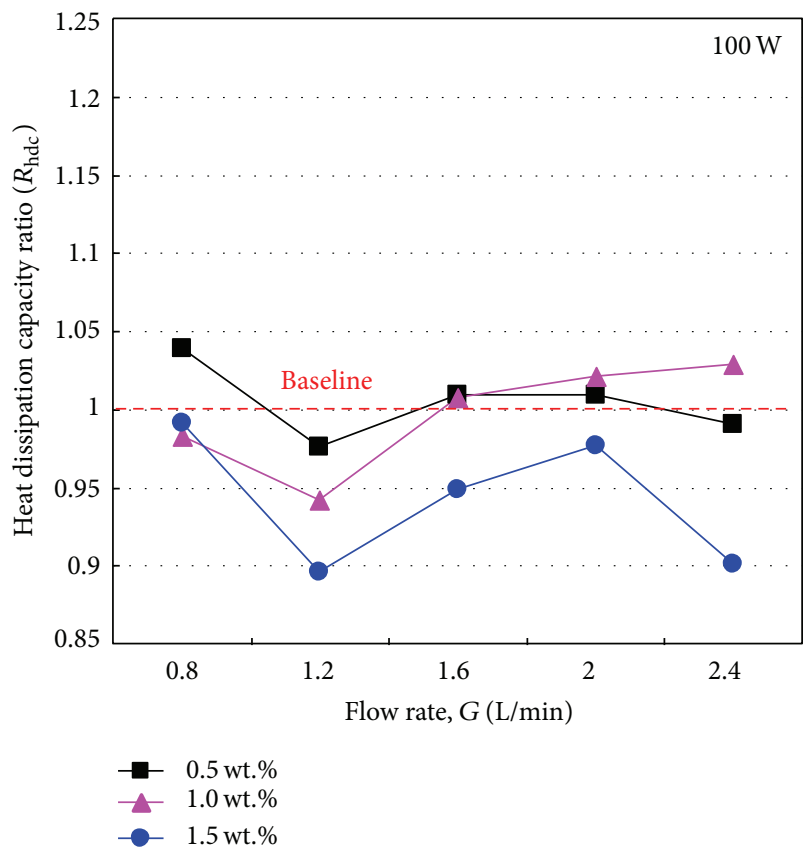

FIGURE 5: Heat dissipation capacity ratio of $\mathrm{Al}_{2} \mathrm{O}_{3}$ /water nanofluid at various flow rates and concentrations with heat generation of $100 \mathrm{~W}$.

performance under a standstill condition because of the water surface tension, adsorbability of water, and the Brown movement of nanoparticles. The thermal conductivity of $\mathrm{Al}_{2} \mathrm{O}_{3}$ /water increases with the $\mathrm{Al}_{2} \mathrm{O}_{3}$ concentration. However, the separation of water and nanoparticles occurs because of the various moving speeds, which are caused by the differing densities at the flowing condition. Therefore, separation between nanoparticles and water forms a thermal layer to reduce the heat dissipation. This phenomenon is more obvious at higher concentrations of nanoparticles. Hence, the increasing concentration of $\mathrm{Al}_{2} \mathrm{O}_{3}$ nanoparticles may 


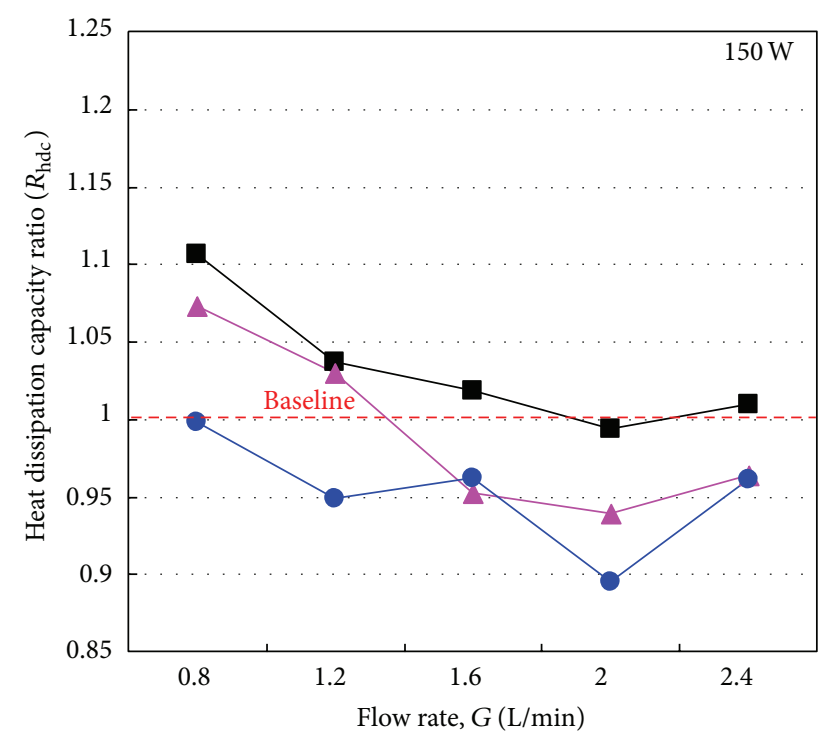

$-\quad 0.5$ wt. $\%$
$-\quad 1.0$ wt. $\%$
$-\quad 1.5$ wt. $\%$

FIgURE 6: Heat dissipation capacity ratio of $\mathrm{Al}_{2} \mathrm{O}_{3}$ /water nanofluid at various flow rates and concentrations with heat generation of $150 \mathrm{~W}$.

not increase the heat dissipation of nanofluid. In addition, the tube type of the selected heat exchanger was a flat tube $(1.9 \times 17.3 \mathrm{~mm}$ cross-sectional area), and the higher viscosity caused by the higher concentration resulted in the unequal flow speed along the cross-sectional area. Hence, the inhomogeneous mix of nanoparticle/water causes the decrease of heat transfer performance.

Figures 7, 8, and 9 show the pumping power consumption ratios $\left(R_{\mathrm{ppc}} \equiv \dot{Q}_{p, \mathrm{nf}} / Q_{p \text {, bf }}\right)$ at various flow rates and concentrations. These figures show that most pumping powers for nanofluids are slightly lower than those of water (within 6\%). This occurs because the nanoparticles provide a lubrication effect between the coolant and the tube. However, the increase of the coolant flow rate of nanofluids causes higher pumping power consumption compared with water. Although the pumping power is expected to increase for the higher concentration of nanoparticles (higher viscosity of nanofluids), the experimental results indicated that the maximal pumping power consumption ratio mostly occurred at the lowest concentration $(0.5 \mathrm{wt} . \%)$. This is the result of the tradeoff between the lubrication effect and viscosity. To realize the overall effect of nanofluids for the proposed heat dissipation system, the concept of efficiency factor ratios in (11) was used.

Figure 10 shows a comparison of the efficiency factor ratios of $\mathrm{Al}_{2} \mathrm{O}_{3}$ /water nanofluid and concludes the results from Figures 4 to 9 . At $50 \mathrm{~W}$, the values of $R_{\mathrm{EF}}$ of three concentrations were maximized (approximately 1.24-1.31) at $0.8 \mathrm{~L} / \mathrm{min}$. This occurred because of the high heat dissipation capability divided by the low pumping power consumption compared with water expressed in (7). For high heat dissipation capacity, because the steady-state temperature was

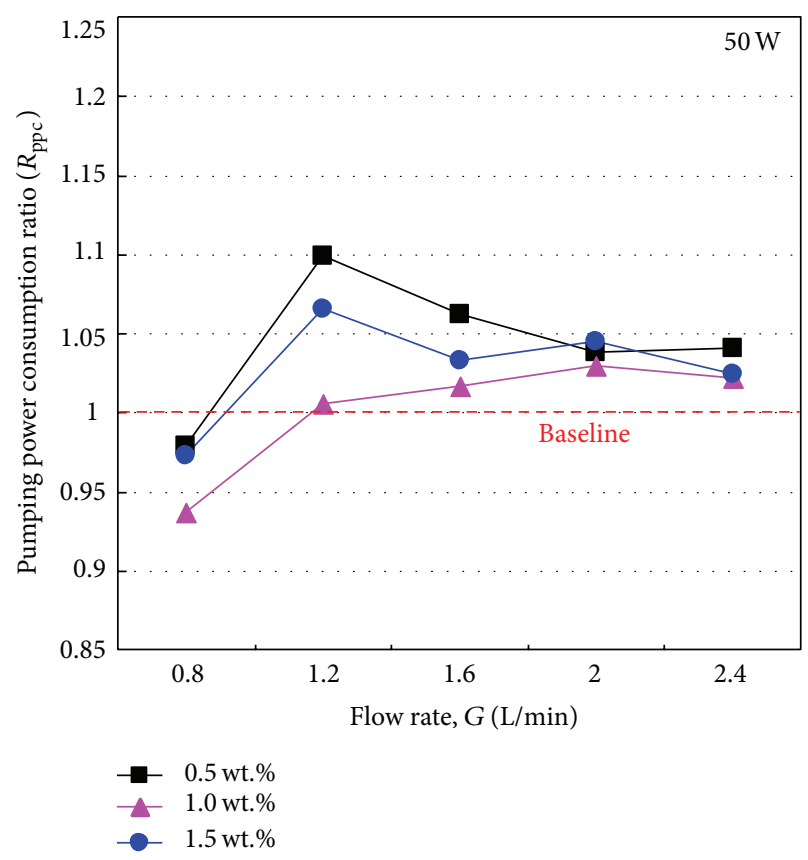

Figure 7: Pumping power consumption ratio of $\mathrm{Al}_{2} \mathrm{O}_{3}$ /water nanofluid at various flow rates and concentrations with heat generation of $50 \mathrm{~W}$.

higher at a low flow rate, based on "Brownian motion" theory, a more intense motion of nanoparticles occurs at high temperature or low viscosity (Table 1), whereas the heat transfer of nanofluid to the tube surface of the heat exchanger was superior. From the macroscale viewpoint, because of the flat tube, it was easier for the low-concentration nanofluid with lower viscosity to spread from the middle to the edge of the tube. By contrast, the increase of viscosity (concentration) strengthens the phenomenon of uneven flow and causes a reduction of the effective heat transfer area. The pumping power consumption decreases at a lower flow rate and viscosity of working fluid. The low flow rate results in a higher temperature and reduces the viscosity. Therefore, the flow resistance decreases, which reduces the power consumption of the pump.

At higher flow rates, all values of $R_{\mathrm{EF}}$ were below 1.0, which indicates that the system performance is lower than that of the baseline water. The minimal value was 0.862 at $1.6 \mathrm{~L} / \mathrm{min}$ and $1.5 \mathrm{wt} . \%$. This indicates that a higher concentration may not guarantee superior heat dissipation. $R_{\mathrm{EF}}$ at $1.5 \mathrm{wt} . \%$ increased slightly at middle flow rates (1.2 and $1.6 \mathrm{~L} / \mathrm{min}$.) because of the comparatively high value of $\dot{m}$ (or $\rho_{l}$ ) according to (1) and (2). At a high flow rate, the stable temperature is lower, which results in a higher density of the nanofluid compared to water (Table 1). Therefore, the value of the mass flow rate and heat dissipation capacity increased.

For the case of $100 \mathrm{~W}$, the maximal values (1.00 to 1.09 ) of $R_{\text {hdc }}$ occurred at $0.8 \mathrm{~L} / \mathrm{min}$. At higher rising flow rates, all values of $R_{\text {hdc }}$ were below 1 , as calculated using (10). The minimal value was 0.854 at $1.2 \mathrm{~L} / \mathrm{min}$ and $1.5 \mathrm{wt} . \%$. Figure 10 shows that the values of $R_{\mathrm{EF}}$ for the case of $1.0 \mathrm{wt} . \%$ are slightly higher than those for $0.5 \mathrm{wt} . \%$ and $1.5 \mathrm{wt} . \%$ because of 


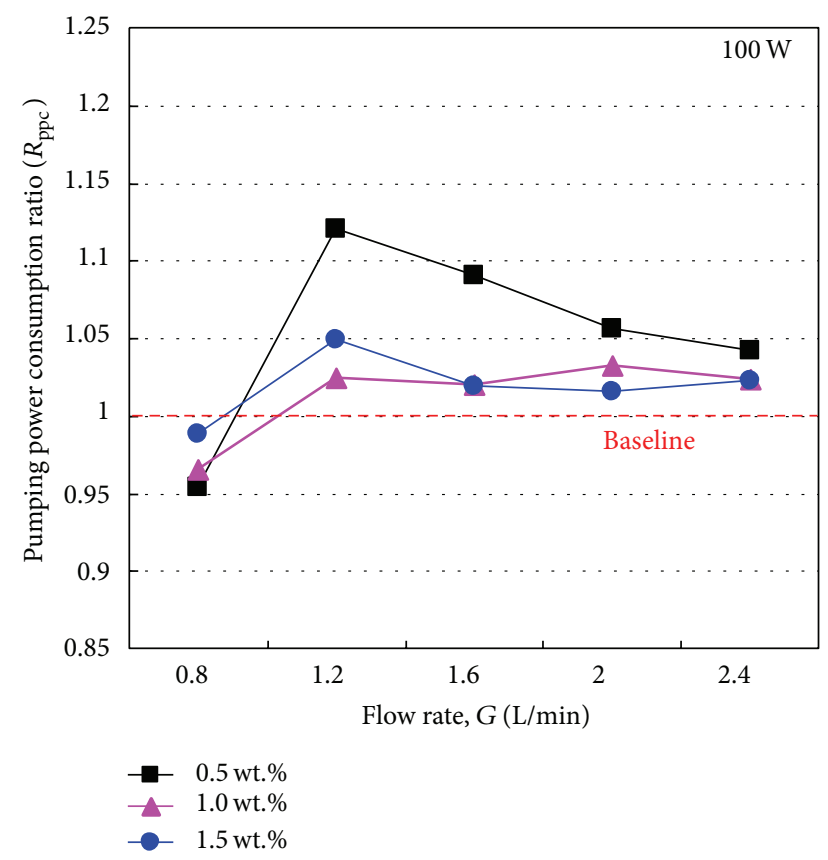

FIgURE 8: Pumping power consumption ratio of $\mathrm{Al}_{2} \mathrm{O}_{3}$ /water nanofluid at various flow rates and concentrations with heat generation of $100 \mathrm{~W}$.

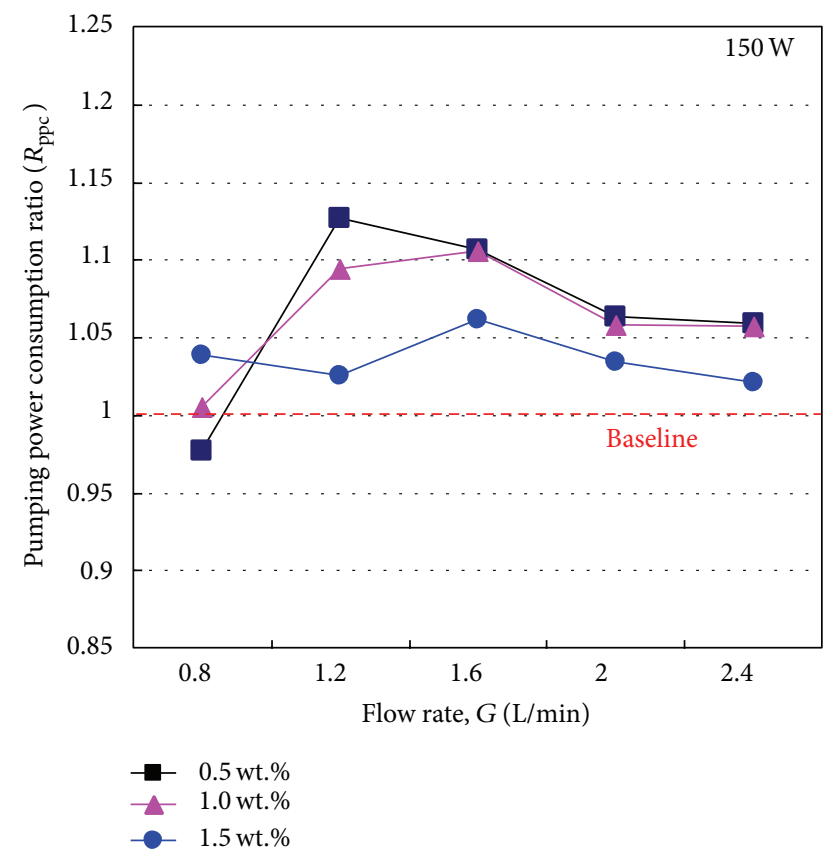

FIgURE 9: Pumping power consumption ratio of $\mathrm{Al}_{2} \mathrm{O}_{3}$ /water nanofluid at various flow rates and concentrations with heat generation of $150 \mathrm{~W}$.

the superior heat dissipation capacity. The measured pumping power consumption enhancement at $1.0 \mathrm{wt} . \%$ was lower than that at $0.5 \mathrm{wt} . \%$ and $1.5 \mathrm{wt} . \%$.

For the case of $150 \mathrm{~W}$, the optimal system performance occurred at a low flow rate of $0.8 \mathrm{~L} / \mathrm{min}$. The maximal value (1.132) occurred at a low concentration of $0.5 \mathrm{wt} . \%$. The case

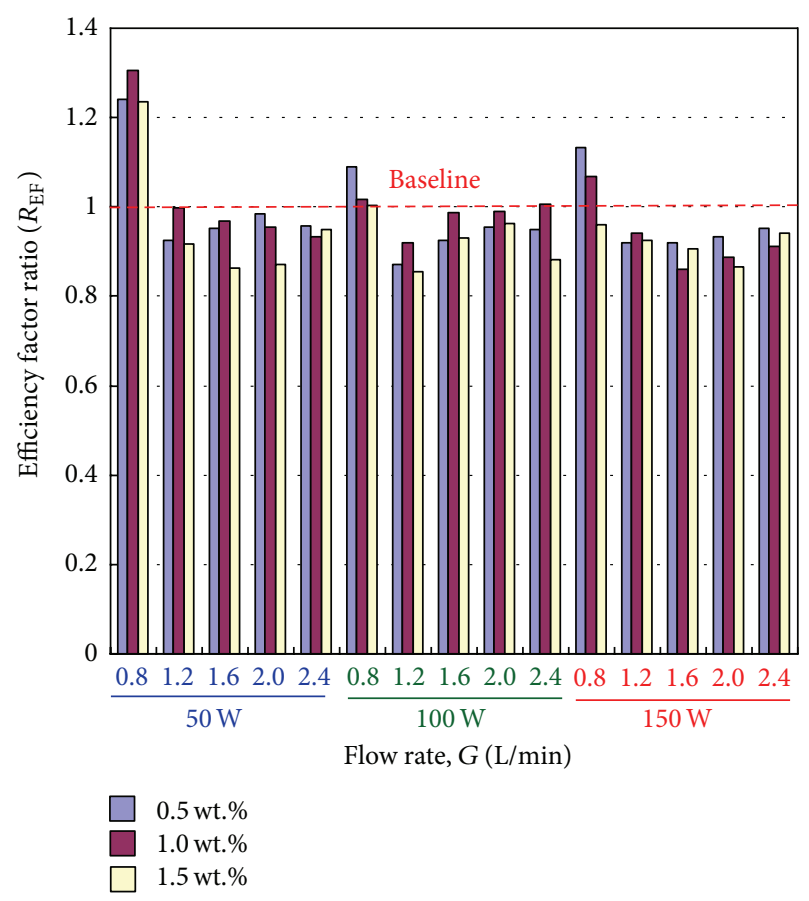

FIGURE 10: Efficiency factor ratio at various flow rates and concentrations with heat generation of $50 \mathrm{~W}, 100 \mathrm{~W}$, and $150 \mathrm{~W}$.

of $1.5 \mathrm{wt} . \%$ dropped below 1 (0.96) because of the lower heat dissipation capacity and higher pumping power compared with water. At middle-to-high flow rates (1.2 to $2.4 \mathrm{~L} / \mathrm{min})$, the values of $R_{\mathrm{hdc}}$ were below 1 , and the minimal value was 0.861 at $1.6 \mathrm{~L} / \mathrm{min}$ and $1.0 \mathrm{wt} . \%$. The experimental analysis indicated that nanofluid at low flow rates can reduce the pumping power consumption and enhance the heat dissipation capacity compared to distilled water. At high concentrations (1.5 wt.\%) and temperatures (higher heating power), heat dissipation may be ineffective. This occurs because the decrease in density and surface tension of bulk liquid may result in inferior suspension performance of nanoparticles, which causes the sediment problem. Therefore, higher concentrations at higher temperatures may cause the degradation of heat transfer because of inferior suspension performance.

From above, high flow rates may reduce the heat dissipation performance. Because of the considerable difference of densities between nanoparticles and water, the separation of nanoparticles and bulk liquid may occur at high flow rates and result in the uneven density of nanofluids. This phenomenon increases the interface thermal resistance and heat transfer instability of nanofluids. About the effect of concentrations, higher concentration may cause higher thermal conductivity; however, the viscosity might largely increase as well. Heat convection (heat exchange capability) is influenced by fluid viscosity, tube surface, and tube geometry. In this study, tubes in the heat exchanger are chosen to be the flattype with a large length/width ratio. Hence, as the fluid flows through flat tubes, the distribution of fluid velocity might vary from the center to the edge of the tube which might cause the decrease of the effective heat exchange surface area. 
Therefore, the research results in this study show that the nanofluid with lower concentration has better heat exchange performance.

\section{Conclusion}

The feasibility of using $\mathrm{Al}_{2} \mathrm{O}_{3}$ /water nanofluid in an aircooled heat exchanger for green energy sources was experimentally assessed. The zeta potential of nanoparticles, relationships of viscosities, and densities and specific heat regarding concentrations and temperatures were examined for further use. After applying basic thermal/physical principles and conducting uncertainty analysis, an experimental setup was established. The testing conditions were three concentrations of $0.5,1.0$, and $1.5 \mathrm{wt} . \%$; five fluid flow rates of $0.8,1.2,1.6,2.0$, and $2.4 \mathrm{~L} / \mathrm{min}$; three cases of heating power of 50,100 , and $150 \mathrm{~W}$. A novel concept of the efficiency factor was proposed to evaluate the enhancement of the efficiency factor compared with distilled water. The experimental results showed that the efficiency factor ratios are optimal at a low flow rate $(0.8 \mathrm{~L} / \mathrm{min})$ and low concentrations $(0.5 \%)$. The maximal $R_{\mathrm{EF}}$ was 1.31 at $50 \mathrm{~W}-0.8 \mathrm{~L} / \mathrm{min}-1.0 \mathrm{wt} . \%$. The values of $R_{\mathrm{hdc}}$ were below 1.0 at high flow rates $(1.2-2.4 \mathrm{~L} / \mathrm{min})$. To examine the two performance indices (heat dissipation capacity and pumping power consumption), the enhancement of heat dissipation capacity was optimized at low flow rates for three concentrations and below 1.0 at high flow rates. The pumping power consumption ratios were higher at middle flow rates $(1.2$ and $1.6 \mathrm{~L} / \mathrm{min})$. This study presents an approach to optimizing a thermal management system for green power sources in the future.

\section{Conflict of Interests}

The authors declare that they have no conflict of interests.

\section{Acknowledgments}

The authors would like to thank National Science Council of the Republic of China, Taiwan, for their financial support to this research under Contracts nos.: NSC 101-2221-E-003-014and NSC 102-2221-E-003-018-, respectively.

\section{References}

[1] J. Baker, "New technology and possible advances in energy storage," Energy Policy, vol. 36, no. 12, pp. 4368-4373, 2008.

[2] K. T. Chau and Y. S. Wong, "Hybridization of energy sources in electric vehicles," Energy Conversion and Management, vol. 42, no. 9, pp. 1059-1069, 2001.

[3] T. Markel, A. Brooker, T. Hendricks et al., "ADVISOR: a systems analysis tool for advanced vehicle modeling," Journal of Power Sources, vol. 110, no. 2, pp. 255-266, 2002.

[4] A. Bejan, G. Tsatsaronis, and M. J. Moran, Thermal Design and Optimizations, John Wiley \& Sons, Ontario, Canada, 1996.

[5] Y. Zhang, M. Ouyang, Q. Lu, J. Luo, and X. Li, "A model predicting performance of proton exchange membrane fuel cell stack thermal systems," Applied Thermal Engineering, vol. 24, no. 4, pp. 501-513, 2004.
[6] X. Yu, B. Zhou, and A. Sobiesiak, "Water and thermal management for Ballard PEM fuel cell stack," Journal of Power Sources, vol. 147, no. 1-2, pp. 184-195, 2005.

[7] J. Nolan and J. Kolodziej, "Modeling of an automotive fuel cell thermal system," Journal of Power Sources, vol. 195, no. 15, pp. 4743-4752, 2010.

[8] G. Vasu and A. K. Tangirala, "Control-orientated thermal model for proton-exchange membrane fuel cell systems," Journal of Power Sources, vol. 183, no. 1, pp. 98-108, 2008.

[9] P. Hu, G. Cao, X. Zhu, and M. Hu, "Coolant circuit modeling and temperature fuzzy control of proton exchange membrane fuel cells," International Journal of Hydrogen Energy, vol. 35, no. 17, pp. 9110-9123, 2010.

[10] D. Andrew and L. James, Fuel Cell Explained, SAE International, Troy, Mich, USA; John Wiley \& Sons, New York, NY, USA, 2003.

[11] M. S. Wu, K. H. Liu, Y. Y. Wang, and C. C. Wan, "Heat dissipation design for lithium-ion batteries," Journal of Power Sources, vol. 109, no. 1, pp. 160-166, 2002.

[12] S. C. Chen, C. C. Wan, and Y. Y. Wang, "Thermal analysis of lithium-ion batteries," Journal of Power Sources, vol. 140, no. 1, pp. 111-124, 2005.

[13] N. Sato, "Thermal behavior analysis of lithium-ion batteries for electric and hybrid vehicles," Journal of Power Sources, vol. 99, no. 1-2, pp. 70-77, 2001.

[14] A. A. Pesaran, "Battery thermal management in EVs and HEVs: issues and solutions," in Proceedings of the Advanced Automotive Battery Conference, Las Vegas, Nev, USA, February 2001.

[15] M. Al Sakka, H. Gualous, J. Van Mierlo, and H. Culcu, “Thermal modeling and heat management of supercapacitor modules for vehicle applications," Journal of Power Sources, vol. 194, no. 2, pp. 581-587, 2009.

[16] J. A. Eastman, S. U. S. Choi, S. Li, W. Yu, and L. J. Thompson, "Anomalously increased effective thermal conductivities of ethylene glycol-based nanofluids containing copper nanoparticles," Applied Physics Letters, vol. 78, no. 6, pp. 718-720, 2001.

[17] H. Xie, J. Wang, T. Xi, Y. Liu, F. Ai, and Q. Wu, "Thermal conductivity enhancement of suspensions containing nanosized alumina particles," Journal of Applied Physics, vol. 91, no. 7, pp. 4568-4572, 2002.

[18] S. K. Das, N. Putra, P. Thiesen, and W. Roetzel, “Temperature dependence of thermal conductivity enhancement for nanofluids," Journal of Heat Transfer, vol. 125, no. 4, pp. 567-574, 2003.

[19] M. Chandrasekar, S. Suresh, and A. Chandra Bose, "Experimental investigations and theoretical determination of thermal conductivity and viscosity of $\mathrm{Al}_{2} \mathrm{O}_{3}$ /water nanofluid," Experimental Thermal and Fluid Science, vol. 34, no. 2, pp. 210-216, 2010.

[20] C. S. Jwo, L. Y. Jeng, T. P. Teng, and C. C. Chen, "Performance of overall heat transfer in multi-channel heat exchanger by alumina nanofluid," Journal of Alloys and Compounds, vol. 504, supplement 1, pp. S385-S388, 2010.

[21] T. P. Teng, Y. H. Hung, T. C. Teng, and J. H. Chen, "Performance evaluation on an air-cooled heat exchanger for alumina nanofluid under laminar flow," Nanoscale Research Letters, vol. 6, no. 488, pp. 1-11, 2011.

[22] P. Keblinski, S. R. Phillpot, S. U. S. Choi, and J. A. Eastman, "Mechanisms of heat flow in suspensions of nano-sized particles (nanofluids)," International Journal of Heat and Mass Transfer, vol. 45, no. 4, pp. 855-863, 2001.

[23] J. Buongiorno, D. C. Venerus, N. Prabhat et al., "A benchmark study on the thermal conductivity of nanofluids," Journal of Applied Physics, vol. 106, no. 9, Article ID 094312, 14 pages, 2009. 
[24] S. Zeinali Heris, M. Nasr Esfahany, and S. G. Etemad, "Experimental investigation of convective heat transfer of $\mathrm{Al}_{2} \mathrm{O}_{3}$ /water nanofluid in circular tube," International Journal of Heat and Fluid Flow, vol. 28, no. 2, pp. 203-210, 2007.

[25] W. Williams, J. Buogiorno, and L. Hu, "Experimental investigation of turbulent convective heat transfer and pressure loss of alumina/water and zirconia/water nanoparticle colloids (nanofluids) in horizontal tubes," Journal of Heat Transfer, vol. 130, no. 4, Article ID 042412, 7 pages, 2008.

[26] K. V. Sharma, L. S. Sundar, and P. K. Sarma, "Estimation of heat transfer coefficient and friction factor in the transition flow with low volume concentration of $\mathrm{Al}_{2} \mathrm{O}_{3}$ nanofluid flowing in a circular tube and with twisted tape insert," International Communications in Heat and Mass Transfer, vol. 36, no. 5, pp. 503-507, 2009.

[27] M. Chandrasekar, S. Suresh, and A. Chandra Bose, "Experimental studies on heat transfer and friction factor characteristics of $\mathrm{Al}_{2} \mathrm{O}_{3}$ /water nanofluid in a circular pipe under laminar flow with wire coil inserts," Experimental Thermal and Fluid Science, vol. 34, no. 2, pp. 122-130, 2010.

[28] S. Suresh, M. Chandrasekar, and S. Chandra Sekhar, "Experimental studies on heat transfer and friction factor characteristics of $\mathrm{CuO}$ /water nanofluid under turbulent flow in a helically dimpled tube," Experimental Thermal and Fluid Science, vol. 35, no. 3, pp. 542-549, 2011.

[29] R. Y. Chein and J. Chuang, "Experimental microchannel heat sink performance studies using nanofluids," International Journal of Thermal Sciences, vol. 46, no. 1, pp. 57-66, 2007.

[30] M. N. Pantzali, A. G. Kanaris, K. D. Antoniadis, A. A. Mouza, and S. V. Paras, "Effect of nanofluids on the performance of a miniature plate heat exchanger with modulated surface," International Journal of Heat and Fluid Flow, vol. 30, no. 4, pp. 691-699, 2009.

[31] A. Zamzamian, S. N. Oskouie, A. Doosthoseini, A. Joneidi, and M. Pazouki, "Experimental investigation of forced convective heat transfer coefficient in nanofluids of $\mathrm{Al}_{2} \mathrm{O}_{3} / \mathrm{EG}$ and $\mathrm{CuO} / \mathrm{EG}$ in a double pipe and plate heat exchangers under turbulent flow," Experimental Thermal and Fluid Science, vol. 35, no. 3, pp. 495-502, 2011.

[32] D. P. Kulkarni, R. S. Vajjha, D. K. Das, and D. Oliva, "Application of aluminum oxide nanofluids in diesel electric generator as jacket water coolant," Applied Thermal Engineering, vol. 28, no. 14-15, pp. 1774-1781, 2008.

[33] A. G. A. Nnanna, W. Rutherford, W. Elomar, and B. Sankowski, "Assessment of thermoelectric module with nanofluid heat exchanger," Applied Thermal Engineering, vol. 29, no. 2-3, pp. 491-500, 2009.

[34] C. J. Ho, L. C. Wei, and Z. W. Li, "An experimental investigation of forced convective cooling performance of a microchannel heat sink with $\mathrm{Al}_{2} \mathrm{O}_{3}$ /water nanofluid," Applied Thermal Engineering, vol. 30, no. 2-3, pp. 96-103, 2010.

[35] B. Farajollahi, S. G. Etemad, and M. Hojjat, "Heat transfer of nanofluids in a shell and tube heat exchanger," International Journal of Heat and Mass Transfer, vol. 53, no. 1-3, pp. 12-17, 2010.

[36] Y. H. Hung, T. P. Teng, T. C. Teng, and J. H. Chen, "Assessment of heat dissipation performance for nanofluid," Applied Thermal Engineering, vol. 32, no. 1, pp. 132-140, 2012.

[37] J. Y. Jung, H. S. Oh, and H. Y. Kwak, "Forced convective heat transfer of nanofluids in microchannels," International Journal of Heat and Mass Transfer, vol. 52, no. 1-2, pp. 466-472, 2009.
[38] W. Duangthongsuk and S. Wongwises, "Heat transfer enhancement and pressure drop characteristics of $\mathrm{TiO}_{2}$-water nanofluid in a double-tube counter flow heat exchanger," International Journal of Heat and Mass Transfer, vol. 52, no. 7-8, pp. 20592067, 2009.

[39] E. Firouzfar, M. Soltanieh, S. H. Noie, and S. H. Saidi, "Energy saving in HVAC systems using nanofluid," Applied Thermal Engineering, vol. 31, no. 8-9, pp. 1543-1545, 2011.

[40] M. Saeedinia, M. A. Akhavan-Behabadi, and M. Nasr, "Experimental study on heat transfer and pressure drop of nanofluid flow in a horizontal coiled wire inserted tube under constant heat flux," Experimental Thermal and Fluid Science, vol. 36, pp. 158-168, 2012.

[41] S. D. Pandey and V. K. Nema, "Experimental analysis of heat transfer and friction factor of nanofluid as a coolant in a corrugated plate heat exchanger," Experimental Thermal and Fluid Science, vol. 38, pp. 248-256, 2012.

[42] B. C. Pak and Y. I. Cho, "Hydrodynamic and heat transfer study of dispersed fluids with submicron metallic oxide particles," Experimental Heat Transfer, vol. 11, no. 2, pp. 151-170, 1998.

[43] Z. H. Liu and Q. Z. Zhu, "Application of aqueous nanofluids in a horizontal mesh heat pipe," Energy Conversion and Management, vol. 52, no. 1, pp. 292-300, 2011.

[44] H. C. Brinkman, "The viscosity of concentrated suspensions and solutions," The Journal of Chemical Physics, vol. 20, no. 4, p. $571,1952$.

[45] T. X. Phuoc, M. Massoudi, and R. Chen, "Viscosity and thermal conductivity of nanofluids containing multi-walled carbon nanotubes stabilized by chitosan," International Journal of Thermal Sciences, vol. 50, no. 1, pp. 12-18, 2011. 

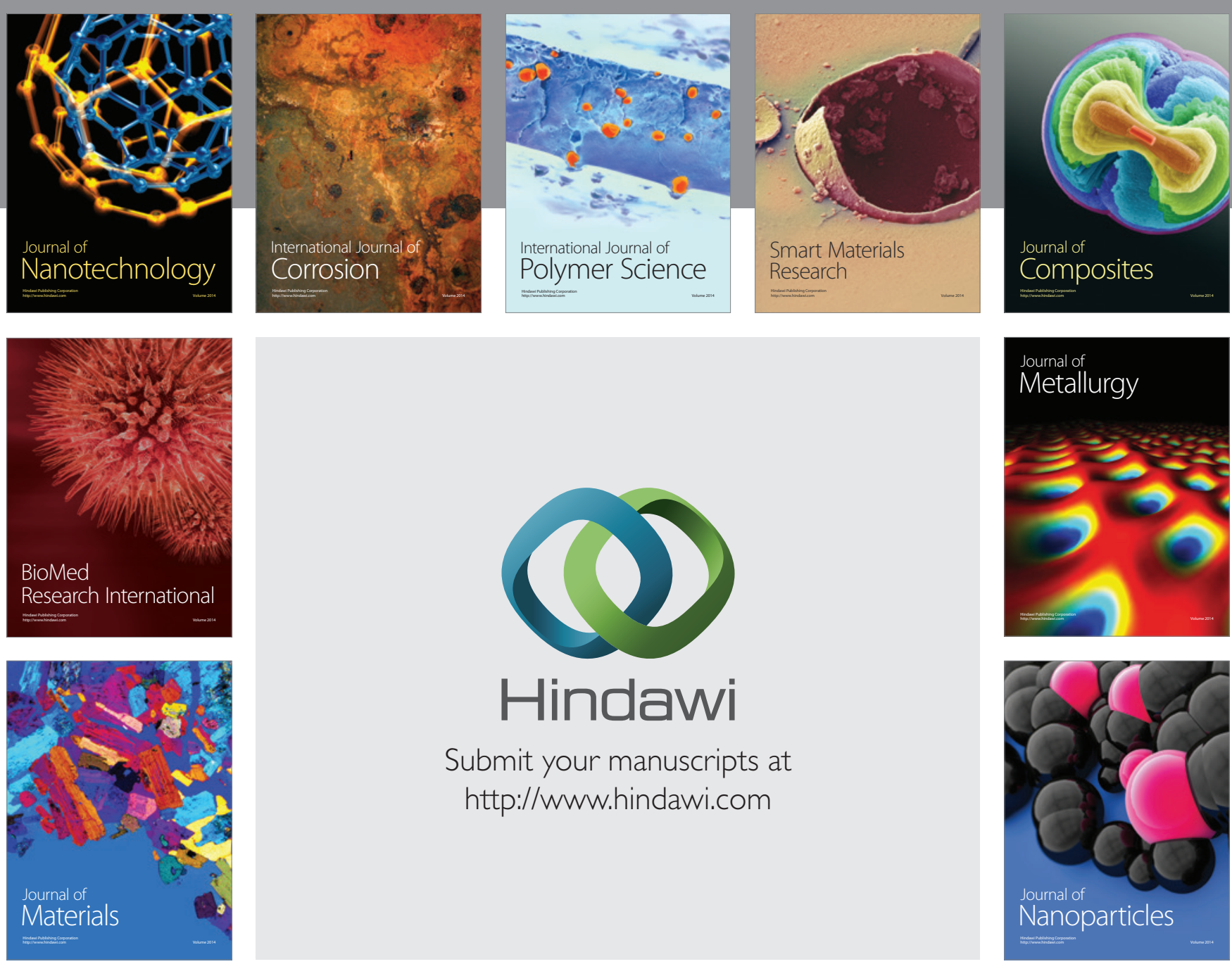

Submit your manuscripts at http://www.hindawi.com
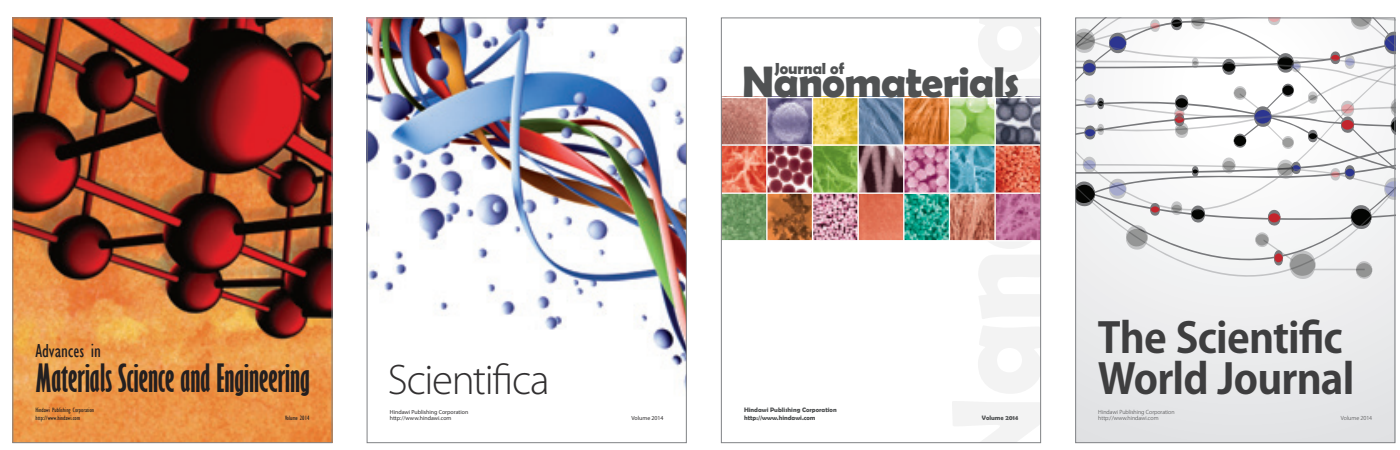

\section{The Scientific World Journal}
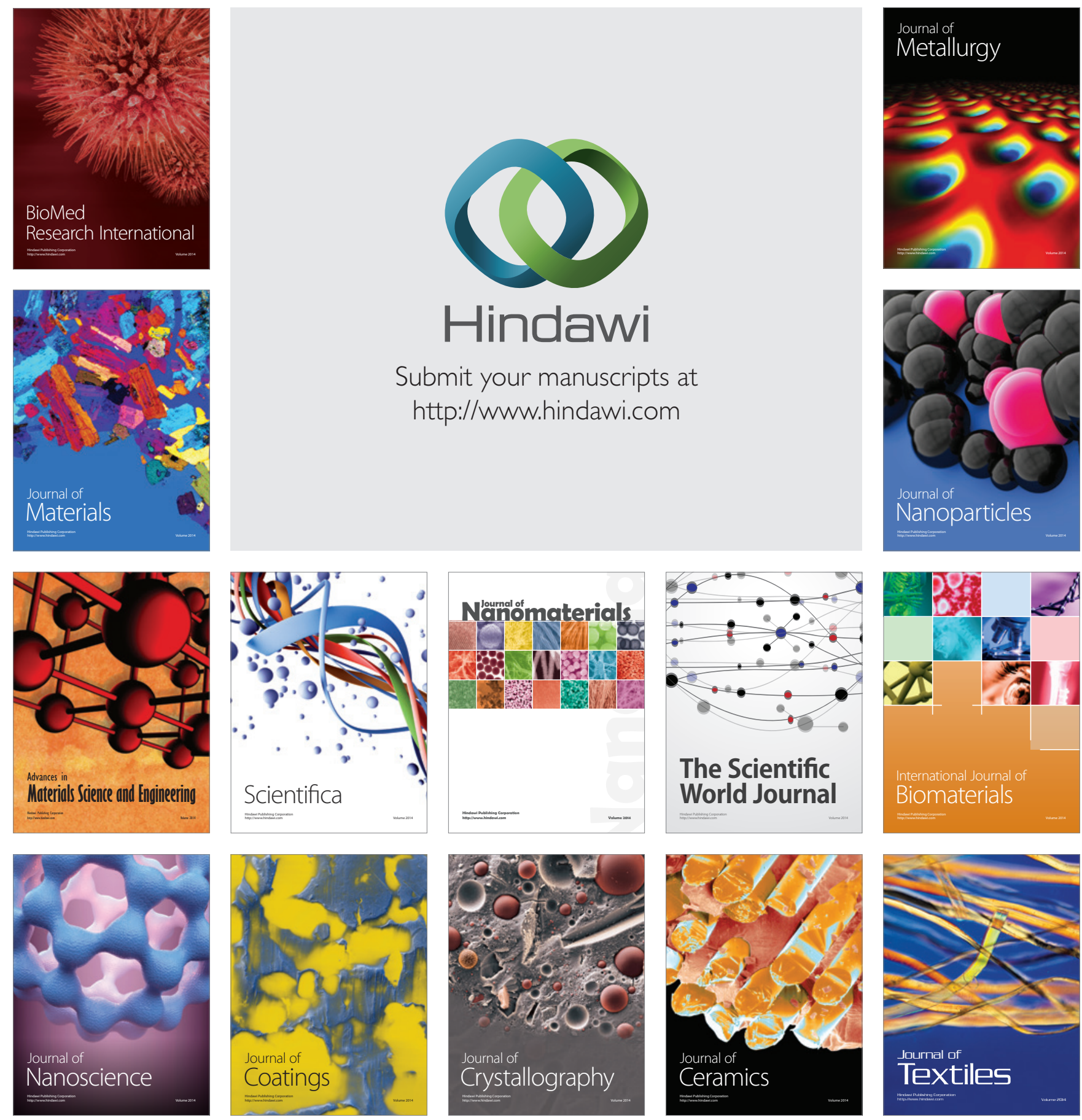